\title{
3 次元数值波動水槽における津波波力に関する適用性の検討
}

\author{
有川太郎* ・ 山田文則 ${ }^{* *}$ ・秋山 実**
}

\begin{abstract}
2 次元数值波動水路（CADMAS-SURF）の計算手法を基に，3 次元数值波動水槽（CADMAS-SUFR/3D）の開発を行 い，砕波や段波のような衝撃的な圧力を伴う波力現象を設計に耐えうる精度で計算できる実用的なモデル構築を目標とした. 本計算では, 同時に並列化システムを導入した. モデルの妥当性を確認するため, 護岸に作用する段波波圧および陸上遡上 する津波段波波圧の計算を行ったところ, 実験と整合した值が得られ, モデルの妥当性を確認した. また, 並列化システム による計算効率を調べたところ，8CPU を用いた場合，約60\%の計算時間短縮となり，さらに，約 6 倍近い計算領域がとれ ることを確認した。
\end{abstract}

\section{1. はじめに}

CIP-CUP 法を用いた気液界面数值モデル（睦田ら， 1998)，CIP 法を用いた 3 次元固気液多相流数值モデル （川崎・中辻，2002）, MPS 法を用いた気液二相流モデ ル（五十里ら，2004）, MARS 法を用いた数值波動水槽 （永瀬・島田，2000）など，3 次元において砕波や越波, また固体との相互作用（睦田ら，2004）等を扱えるよう になったモデルは多いが，砕波や段波による作用波力を 精度良く計算できる 3 次元モデルは未だ開発途上にあり， そういった波力について現在までのところ，3 次元で実 験との比較を含めてその精度について論じられた研究は ない.

一方で 2 次元計算においては, 数值波動水路一 CADMAS-SURF-（数值波動水路の耐波設計への適用 に関する研究会，2002）により，衝撃波力を高い精度で 計算できることが示されている.

そこで， 2 次元数值波動水路の計算手法を基にし， 3 次元数值波動水槽 (CADMAS-SURF/3D) の開発を行う ことで, 砕波や段波のような衝撃的な圧力を伴う波力現 象を精度良く計算できる 3 次元モデルの構築を目標とし た.

モデルの妥当性を確認するために護岸に作用する段波 津波波力の実験結果との比較を行った。そして、遡上域 が下り勾配となるような地形において実験との比較を行 うとともに、平坦な場合との比較を行い、下り勾配が及 ぼす影響について検討を行った。

\section{2. 基礎方程式と数値計算手法}

3 次元数值波動水槽 (CADMAS-SURF/3D) は, 2 次元数值波動水路（CADMAS-SURF）の計算手法を基 にしたものであり, 自由表面解析モデルにVOF 法を採

* 正会 員 博 (工）（独法）港湾空港技術研究所 特任研究官

** 学生会員 工修 長岡技術科学大学大学院

$* * *$ みずほ情報総研株式会社
用したものである.

\section{（1）基礎方程式}

CADMAS-SURF/3D の基礎方程式は 3 次元非圧縮性 粘性流体を対象とした連続式および Navier-Stokes 方程 式をポーラスモデルに基づいて拡張した式 (1) から (4)である.

$$
\begin{aligned}
& \frac{\partial \gamma_{x} u}{\partial x}+\frac{\partial \gamma_{y} v}{\partial y}+\frac{\partial \gamma_{z} w}{\partial z}=\gamma_{v} S_{\rho} \cdots \ldots \ldots \ldots \ldots \ldots \ldots \\
& \lambda_{v} \frac{\partial_{u}}{\partial t}+\frac{\partial \lambda_{x} u u}{\partial x}+\frac{\partial \lambda_{y} v u}{\partial y}+\frac{\partial \lambda_{z} w u}{\partial z}=-\frac{\gamma_{v}}{\rho} \frac{\partial p}{\partial x} \\
& +\frac{\partial}{\partial x}\left\{\gamma_{x} \nu_{e}\left(2 \frac{\partial u}{\partial x}\right)\right\}+\frac{\partial}{\partial y}\left\{\gamma_{y} \nu_{e}\left(\frac{\partial u}{\partial y}+\frac{\partial v}{\partial x}\right)\right\} \\
& +\frac{\partial}{\partial z}\left\{\gamma_{z} \nu_{e}\left(\frac{\partial u}{\partial z}+\frac{\partial w}{\partial x}\right)\right\}-\gamma_{v} D_{x}-R_{x}+\gamma_{v} S_{u} \cdots \\
& \lambda_{v} \frac{\partial v}{\partial t}+\frac{\partial \lambda_{x} u v}{\partial x}+\frac{\partial \lambda_{y} v v}{\partial y}+\frac{\partial \lambda_{z} w v}{\partial z}=-\frac{\gamma_{v}}{\rho} \frac{\partial p}{\partial y} \\
& +\frac{\partial}{\partial z}\left\{\gamma_{z} \nu_{e}\left(\frac{\partial v}{\partial z}+\frac{\partial w}{\partial y}\right)\right\}-\gamma_{v} D_{y} \nu-R_{y}+\gamma_{v} S_{v} \cdots \\
& \quad+\frac{\partial}{\partial x}\left\{\gamma_{x} \nu_{e}\left(\frac{\partial v}{\partial x}+\frac{\partial u}{\partial y}\right)\right\}+\frac{\partial}{\partial y}\left\{\gamma_{y} \nu_{e}\left(2 \frac{\partial v}{\partial y}\right)\right\}
\end{aligned}
$$

$$
\lambda_{v} \frac{\partial w}{\partial t}+\frac{\partial \lambda_{x} u w}{\partial x}+\frac{\partial \lambda_{y} v w}{\partial y}+\frac{\partial \lambda_{z} w w}{\partial z}=-\frac{\gamma_{v}}{\rho} \frac{\partial p}{\partial z}
$$

$$
+\frac{\partial}{\partial x}\left\{\gamma_{x} \nu_{e}\left(\frac{\partial w}{\partial x}+\frac{\partial u}{\partial z}\right)\right\}+\frac{\partial}{\partial y}\left\{\gamma_{y} \nu_{e}\left(\frac{\partial w}{\partial y}+\frac{\partial v}{\partial z}\right)\right\}
$$

$$
+\frac{\partial}{\partial z}\left\{\gamma_{z} \nu_{e}\left(2 \frac{\partial w}{\partial z}\right)\right\}-\gamma_{v} D_{z} w-R_{z}+\gamma_{v} S_{w}-\frac{\gamma_{v} \rho^{*} g}{\rho}
$$


ここで, $t$ は時間, $x, y$ は水平方向座標, $z$ は鉛直方 向座標, $u, v, w$ は $x, y, z$ 方向の流速成分, $\rho$ は規準 密度, $\rho^{*}$ は浮力を考慮する密度, $p$ は圧力, $\nu_{e}$ は分子 動粘性係数 $\nu$ と渦動粘性係数 $\nu_{t}$ の和, $g$ は重力加速度, $\gamma_{v}$ は空隙率, $\gamma_{x}, \gamma_{y}, \gamma_{z}$ は各方向の面積透過率, $D_{x}$, $D_{y}, D_{z}$ はエネルギー減衰帯のための係数, $S_{\rho}, S_{u}, S_{v}$, $S_{w}$ は造波ソースに関する係数である. $\lambda_{v}, \lambda_{x}, \lambda_{y}, \lambda_{z}$ は構造物から受ける慣性力効果を示したパラメータであ り式 (5)のように求められる.

$$
\left.\begin{array}{l}
\lambda_{v}=\gamma_{v}+\left(1-\gamma_{v}\right) C_{M} \\
\lambda_{x}=\gamma_{x}+\left(1-\gamma_{x}\right) C_{M} \\
\lambda_{y}=\gamma_{y}+\left(1-\gamma_{y}\right) C_{M} \\
\lambda_{z}=\gamma_{z}+\left(1-\gamma_{z}\right) C_{M}
\end{array}\right\}
$$

ここで, $C_{M}$ は慣性力係数である. 多孔質体からの抵抗 力 $R_{x}, R_{y}, R_{z}$ は, 式 (6) のように計算される.

$$
\left.\begin{array}{l}
R_{x}=\frac{1}{2} \frac{C_{D}}{\Delta_{x}}\left(1-\gamma_{x}\right) u \sqrt{u^{2}+v^{2}+w^{2}} \\
R_{y}=\frac{1}{2} \frac{C_{D}}{\Delta_{y}}\left(1-\gamma_{y}\right) v \sqrt{u^{2}+v^{2}+w^{2}} \\
R_{z}=\frac{1}{2} \frac{C_{D}}{\Delta_{z}}\left(1-\gamma_{z}\right) w \sqrt{u^{2}+v^{2}+w^{2}}
\end{array}\right\}
$$

ここで, $C_{D}$ は抵抗係数, $\Delta_{x}, \Delta_{y}, \Delta_{z}$ は各方向の格子 間隔である。

時間方向の離散化は Euler 法で行い, 運動方程式と連 続式の連成には SMAC 法で行う. SMAC 法では, 連立 1 次元方程式の解法が全計算時間の多く 7 割から 9 割以 上を占め, 連続式の精度を通じてスカラー量の保存を大 きく左右する. そのため, 非対称の連立1次元方程式の 解法として収束および安定性の高い前処理付き BCGSTAB 法を用いた。

\section{（2）数值解析手法および境界条件}

\section{a ）自由表面}

自由表面解析モデルは, 汎用性が高く, 複雑な表面形 状を解析可能であるVOF 法を用いて計算を行うＶVOF 法では，本来ステップ関数となる「流体である・ない」 を表す関数を計算セル毎に平均化した VOF 関数 F の移 流方程式と，表面の向きを逐次的に計算することにより， 自由表面の挙動を解析する. ポーラスモデルに基づく VOF 関数 F の移流方程式を式 $(7)$ に示す.

$$
\gamma_{v} \frac{\partial F}{\partial t}+\frac{\partial \gamma_{x} u F}{\partial x}+\frac{\partial \gamma_{y} v F}{\partial y}+\frac{\partial \gamma_{z} w F}{\partial z}=\gamma_{v} S_{F} \cdots
$$

ここで， $S_{F}$ は造波に関する係数である.

b ) 造波モデル

計算モデルでは, 規則波の水位や流速の計算方法とし て, ストークス波第 5 次近似解, クノイド波第 3 次近似
解および流れ関数法 B による数值解の 3 つを用いてい る.ここでの Deanの流れ関数法 B の適用においては, 波速の第 2 定義に基ついて導かれたストークス波やクノ イド波の瞋動解と同様に，波速の第 2 定義に基づく物理 量（水位変動, 流速, 圧力, 波速）を与えるものとする. 不規則波の生成は，任意の水位と流速のデータ（マトリ クスデータ）を作成して入力データとすることで，時間 方向および空間方向に補間しながら計算を行う.また, この造波は斜め入射も可能である.

c）時間刻み幅の計算

数值計算上の時間刻み幅は, 式 (8) および $(9)$ に示 すような CFL 条件または粘性項の安定条件を満足する ように計算を行う。

$$
\begin{aligned}
& \Delta t \leq \min \left(\frac{\Delta x}{u}, \frac{\Delta y}{v}, \frac{\Delta z}{w}\right)=\Delta t_{c} \cdots \cdots \cdots \cdots \cdots \cdots \\
& \Delta t \leq \min \frac{1}{2} \frac{1}{v\left[\left(\frac{1}{\Delta x}\right)^{2}+\left(\frac{1}{\Delta y}\right)^{2}+\left(\frac{1}{\Delta z}\right)^{2}\right]}=\Delta t_{v} \cdots(
\end{aligned}
$$

実際の計算では, 安全係数 $\alpha$ を用いて時間幅を式 (10) で求める.

$$
\Delta t \leq \alpha \min \left(\Delta t_{c}, \Delta t_{v}\right) \cdots
$$

$$
(0.0<\alpha<1.0)
$$

\section{d）並列化システムの構築}

本プログラムを並列化するにあたり，同一のプログラ ムが複数ノードで稼働する SPMD (Single Program Multiple Data) モデルを用いた. また，データの取り 扱いには，大規模計算に適した領域分割法を採用した。

対象とする並列計算機は, 複数の PC をネットワーク 接続した PC クラスターを対象とした。よって，並列計 算機の種類としては, 分散メモリー型である. ただし, 共有メモリー型にすることも可能である. OS はUNIX 準拠, メッセージ交換ライブラリーは, MPI (Message Passing Interface) とした. また，コンパイラは, Intel Fortran 8.0である. 本研究では 9 台（1台は管理マシ ン）の廉価マシンを用いて並列システムを構築した.

その結果，8CPUで計算することにより約 $60 \%$ の計算 時間短縮が行われ, かつ約 6 倍の計算領域をとることが

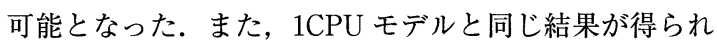
ることを確認した。

\section{3. 計算および境界条件}

\section{（1）陸上遡上の計算}

計算は図-1(a) のような長さ $67 \mathrm{~m} \times$ 幅 $0.04 \mathrm{~m} \times$ 高さ $2.08 \mathrm{~m}$ の 3 次元数值水槽で行った. 図の左側より $1 / 50$ の一定勾配が汀線まで設置してあり, 点線部分が遡上域 
表-1 計算条件

\begin{tabular}{|c|c|c|c|c|c|c|c|c|c|c|c|c|c|c|c|}
\hline \multirow[t]{2}{*}{ 計算ケース } & \multirow[t]{2}{*}{ 方向 } & \multirow{2}{*}{$\begin{array}{c}\text { 汀線からの距離 } \\
\mathrm{m} \\
\end{array}$} & \multirow{2}{*}{\begin{tabular}{|c} 
格子数 \\
個 \\
\end{tabular}} & \multicolumn{2}{|c|}{ 格子間隔 } & \multirow[t]{2}{*}{ 方向 } & \multirow{2}{*}{$\begin{array}{c}\text { 距離 } \\
\mathrm{m} \\
\end{array}$} & \multirow{2}{*}{$\begin{array}{c}\text { 格子数 } \\
\text { 個 } \\
\end{array}$} & \multicolumn{2}{|c|}{ 格子間隔 } & \multirow[t]{2}{*}{ 方向 } & \multirow{2}{*}{$\begin{array}{c}\text { 距離 } \\
\mathrm{m} \text { (水深方向 }- \text { ) } \\
\end{array}$} & \multirow{2}{*}{$\begin{array}{c}\text { 格子数 } \\
\text { 個 }\end{array}$} & \multicolumn{2}{|c|}{ 格子間隔 } \\
\hline & & & & $\mathrm{m}$ & 種類 & & & & $\mathrm{m}$ & 種類 & & & & $\mathrm{m}$ & 種類 \\
\hline \multirow{4}{*}{$\begin{array}{l}\text { 陸上遡上 } \\
\text { 下り勾配 } \\
\text { 水路全体 }\end{array}$} & \multirow{4}{*}{$\mathrm{x}$ 方向 } & $60.0 \sim 10.0$ & 500 & 0.10 & 等間隔 & \multirow[t]{4}{*}{$\mathrm{y}$ 方向 } & $0.00 \sim 0.04$ & 2 & 0.02 & 等間隔 & \multirow[t]{4}{*}{$z$ 方向 } & $-1.00 \sim 0.00$ & 36 & $0.04 \rightarrow 0.02$ & 不等間隔 \\
\hline & & $10.0 \sim 0.0$ & 150 & $0.10 \rightarrow 0.02$ & 不等間隔 & & \multirow{3}{*}{\begin{tabular}{|l|} 
\\
合計 \\
\end{tabular}} & & & $0.00 \sim 1.08$ & 54 & 0.02 & 等間隔 \\
\hline & & $0.0 \sim-7.0$ & 350 & \begin{tabular}{l|}
0.02 \\
\end{tabular} & $\begin{array}{l}\text { 等間隔 } \\
\end{array}$ & & & & & & & & & & \\
\hline & & 合計 & 1000 & & & & & 2 & & & & 合計 & \multicolumn{3}{|l|}{100} \\
\hline \multirow{6}{*}{$\begin{array}{l}\text { 護岸計算 } \\
\text { 水路全体 }\end{array}$} & \multirow{6}{*}{$\mathrm{x}$ 方向 } & $74.00 \sim 50.00$ & 240 & 0.10 & 等間隔 & \multirow[t]{6}{*}{$y$ 方向 } & 0.06 & 3 & 0.02 & 等間隔 & \multirow[t]{6}{*}{$z$ 方向 } & $-1.00 \sim-0.50$ & 13 & $0.04 \rightarrow 0.02$ & 不等間隔 \\
\hline & & $50.00 \sim 25.00$ & 346 & $0.10 \rightarrow 0.05$ & 不等間隔 & & & & & & & $-0.50 \sim 0.00$ & 34 & $0.02 \rightarrow 0.01$ & 不等間隔 \\
\hline & & $25.00 \sim 15.00$ & 305 & $0.05 \rightarrow 0.02$ & 不等間隔 & & & & & & & $0.00 \sim 0.50$ & 50 & 0.01 & 等間隔 \\
\hline & & $15.00 \sim-0.50$ & 775 & 0.02 & 等間隔 & & & & & & & $0.50 \sim 1.00$ & 34 & $0.01 \rightarrow 0.02$ & 不等間隔 \\
\hline & & & & & & & & & & & & $1.00 \sim 1.25$ & 16 & 0.02 & 等間隔 \\
\hline & & 合計 & 1666 & & & & 合計 & 3 & & & & 合計 & 147 & & \\
\hline 護岸 25 m & $\mathrm{x}$ 方向 & $25.00 \sim 20.00$ & 125 & 0.04 & 等間隔 & $\mathrm{y}$ 方向 & 0.3 & 15 & 0.02 & 等間隔 & $z$ 方向 & $-0.50 \sim 0.00$ & 34 & $0.02 \rightarrow 0.01$ & 不等間隔 \\
\hline から計算 & & $20.00 \sim 15.00$ & 172 & $0.04 \rightarrow 0.02$ & 不等間隔 & & & & & & & $0.00 \sim 0.50$ & 50 & 0.01 & 等間隔 \\
\hline & & $15.00 \sim-0.10$ & 755 & 0.02 & 等間隔 & & & & & & & $0.50 \sim 1.00$ & 34 & $0.01 \rightarrow 0.02$ & 不等間隔 \\
\hline & & 合計 & 1052 & & & & 合計 & 15 & & & & 合計 & 118 & & \\
\hline
\end{tabular}

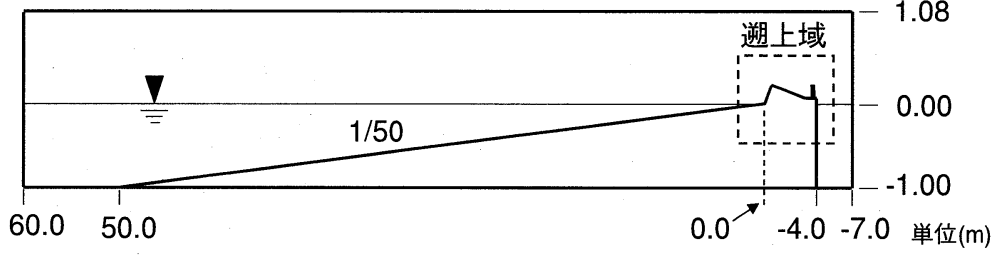

図-1（a）水路全体

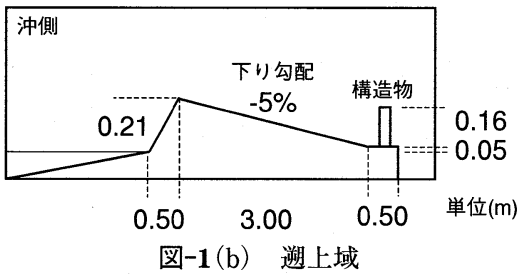

図-1(b) 遡上域

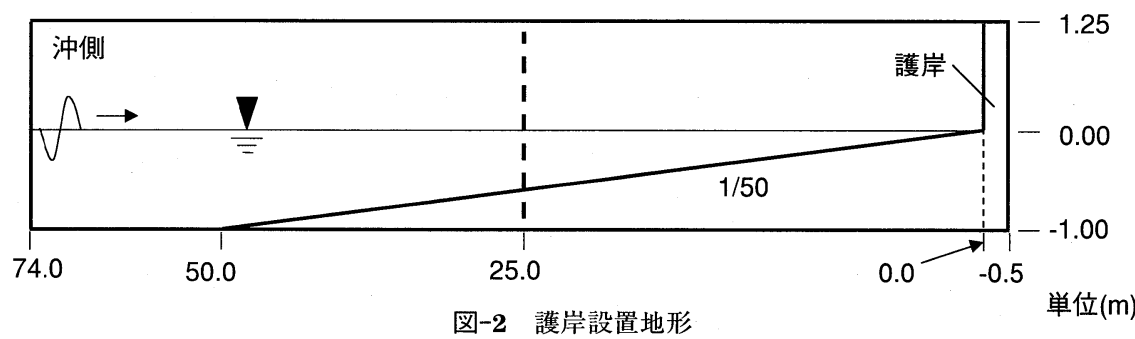

となる.図-1(b) は遡上域の地形を拡大したものであ り，遡上域は汀線から $0.5 \mathrm{~m}$ まで上がり勾配となり，そ の背後にー5\%程度の下り勾配が続いているような地形 である. 汀線から $3.75 \mathrm{~m}$ の地点に長さ $0.12 \mathrm{~m} \times$ 幅 0.04 $\mathrm{m} \times$ 高さ $0.15 \mathrm{~m}$ の構造物を設置し, この構造物に作用 する圧力の計算を行った，造波条件は，汀線から沖側へ $60 \mathrm{~m}$ の位置より，波高 $0.16 \mathrm{~m}$, 周期 $20 \mathrm{~s}$ の押し波津波 を与えた，境界条件は水槽の側面を不透過とし，陸側の 境界面を透過境界として計算を行った，水深は造波位置 で $1.00 \mathrm{~m}$ とした.

\section{（2）護岸に作用する津波段波波力の計算}

地形は, 図-2のような沖側 $50 \mathrm{~m}$ 地点から汀線まで 1/50勾配であり，汀線付近に護岸を設置した。平面地形 の計算と同様に, $\mathrm{Y}$ 方向格子の少ない数值水槽全体の 計算を行い, 汀線から $25 \mathrm{~m}$ の位置での造波デー夕を作 成し，それを用いて護岸前面の詳細な計算を行った。水 槽全体の計算領域は図-2のような長さ $74.50 \mathrm{~m} \times$ 幅 $0.06 \mathrm{~m} \times$ 高さ $2.25 \mathrm{~m}$ の空間であり, 沖側 $74.00 \mathrm{~m}$ の位
置で波高 $0.27 \mathrm{~m}$ ，周期 $20 \mathrm{~s}$ を与えた.

護岸前面の計算領域は長さ $25.10 \mathrm{~m} \times$ 幅 $0.30 \mathrm{~m} \times$ 高 さ $1.5 \mathrm{~m}$ の 3 次元数值水槽で計算を行った. 造波デー夕 は, 水路全体の計算結果から図の中央に位置する $25 \mathrm{~m}$ の位置において作成した. 各計算条件をまとめたものを 表-1に示す.

\section{4. 計算結果および考察}

\section{(1) 陸上遡上の計算}

図-3 は，下り勾配における津波の遡上高を示した時 系列分布である. 図の実線は, 計算地形と同様の模型を 用いた実験結果である. 眓の点線に示す計算結果は, 実 験における津波の遡上高とよく表現できていることがわ かる、ただし，実験では水路幅 $3.50 \mathrm{~m}$ （ $y$ 方向）である が, 計算では計算時間の短縮のために $y$ 方向を $0.04 \mathrm{~m}$ として計算を行っている.

図-4 は下り勾配地形の影響を検討するために，下り 勾配部が平坦な場合の計算結果との比較した結果である. 

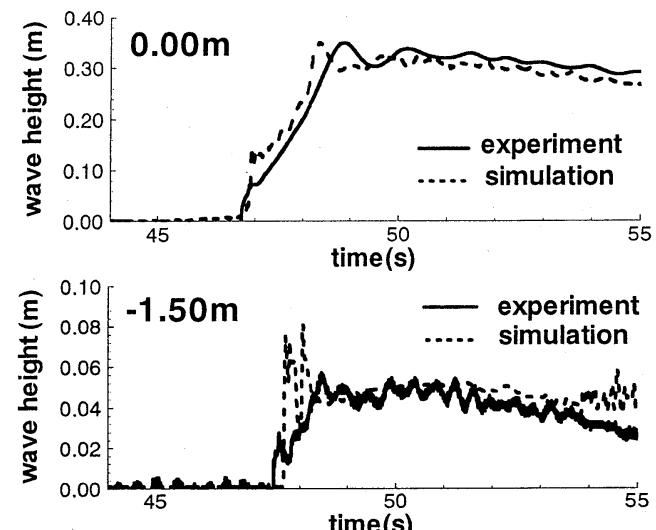

time(s)

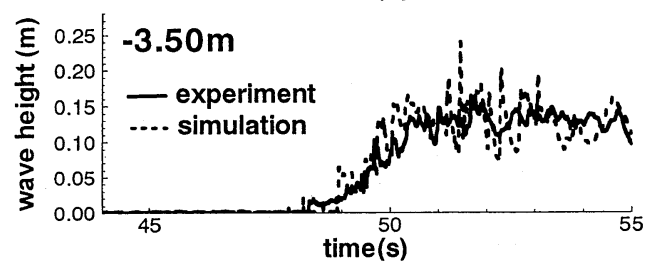

図-3 波高の時系列分布
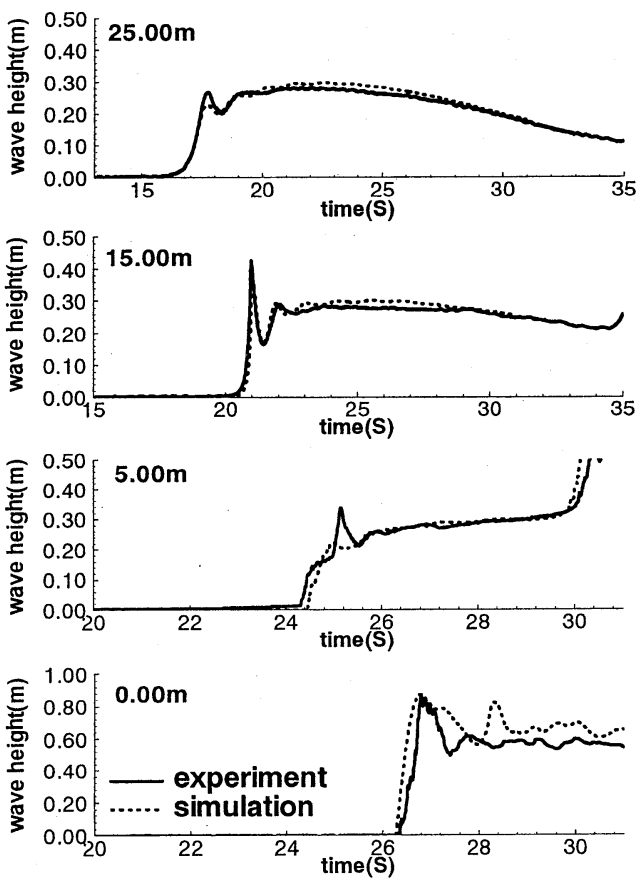

図-6 波高の時系列分布

この図は遡上域に侵入する津波の遡上高さを比較したも のである. 図に示す通り, いずれの結果もほほ同様の值 を示しており，今回のような地形では遡上高に与える下 り勾配の影響は小さかった。図-5 は列車に作用する津 波圧力の計算結果を比較したものである，図に示すよう に，2つの地形では列車に作用する波力は $1.5 \sim 2.0$ 倍程

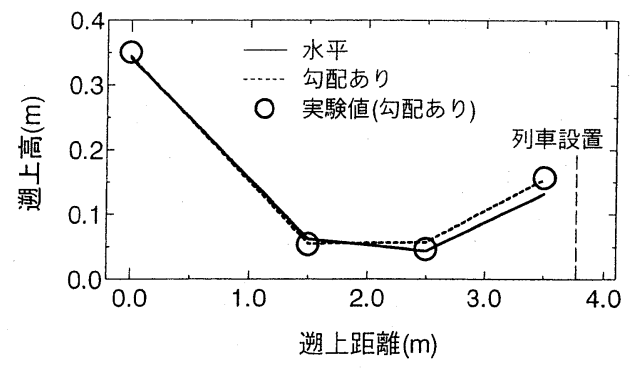

図-4 遡上高の比較

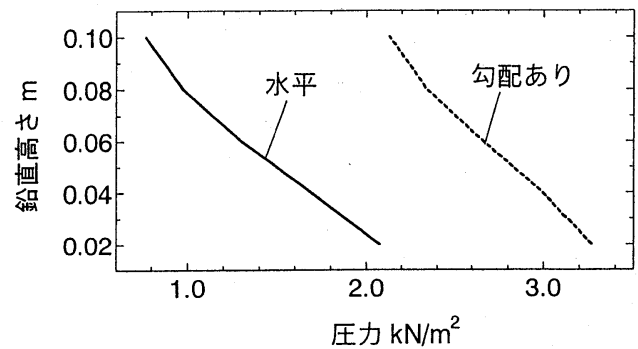

図-5 構造物に作用する圧力
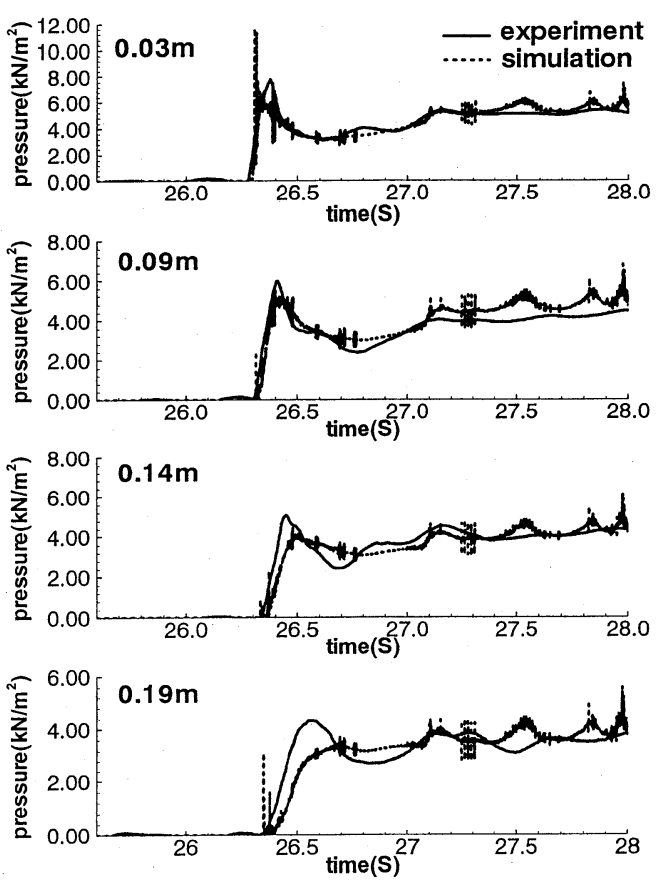

図-7＼cjkstart護岸に作用する圧力

度の差が見られる。これは下り勾配により津波の位置エ ネルギーが運動エネルギーに変換され, 波力に差が生じ たものと考えられる.この結果より, 今回, 列車事故の あったスリランカのように地形が下り勾配となっている 場所では，平坦な場所よりも構造物に作用する波力が大 きくなっていたのではないかと考えられる. 

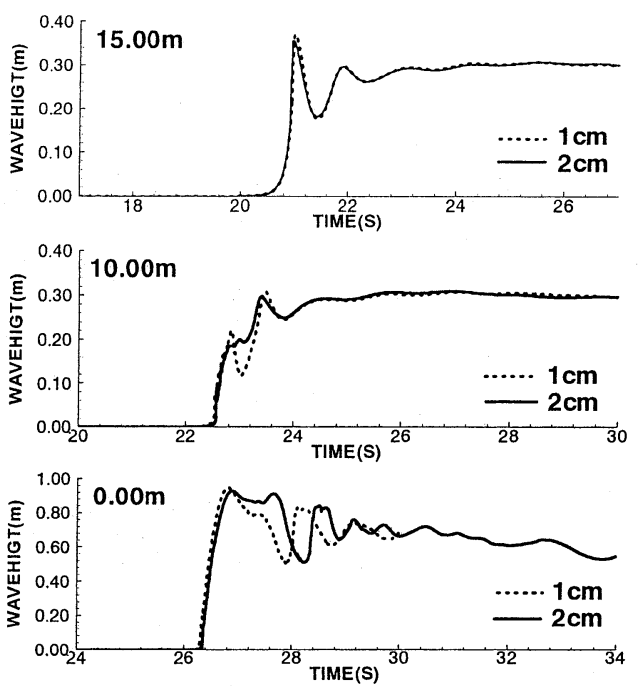

図-8 格子間隔の影響

\section{（2）護岸に作用する津波段波波力の計算}

図-6は津波における波高の時系列分布を表したもの である. 図の実線は図-2 と同様の断面で実験を行った 場合の結果である，ただし，実験の水路幅は $3.5 \mathrm{~m}$ であ り, 今回の造波条件では, 汀線から $12 \mathrm{~m}$ 程度の位置で 砕波点が見られた．図に示すとおり，計算結果は段波状 の波が護岸に作用する場合の実験結果を精度よく計算で きている．この結果より，このような砕波後および波が 護岸に衝突するような非常に非線形の強い流体現象を精 度よく計算できることがわかった. しかしながら，今回 のケースでは，砕波後の波に若干のばらつきが見られる. これは，計算に用いた格子間隔の影響によるものである と考えられる．図-8 は，水面付近の鉛直方向の格子間 隔を変化させた場合の計算結果の比較である. 図の実験 が水面付近の鉛直格子間隔が $2 \mathrm{~cm}$ であり, 点線が $1 \mathrm{~cm}$ で計算を行ったものである，図より，砕波後 $10.0 \mathrm{~m}$ お よび $0 \mathrm{~m}$ の位置ではばらつきが見られる. そのため, 今後, より精度の高い計算結果を行うために，格子間隔 に関して詳細に調べていく必要があると考えられる。

図-7 は護岸に作用した圧力の時系列分布を表したも のである. 図の結果は, 波の衝突時における護岸に作用 する圧力であり, 図の左上の数字は圧力計の静水面から の位置である。図より，波の衝突時に護岸に作用する衝 撃的な津波波力を精度よく計算できることが確認された. 図-9 は波の衝突時に護岸に作用する津波波力の最大值 を示した鉛直分布である．図に示すとおり，計算結果に 少しばらつきが見られるが，護岸全体の作用波圧はよく 計算できている.

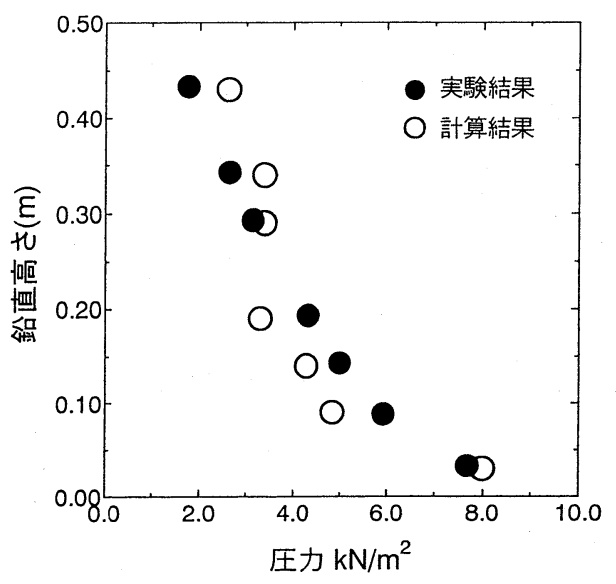

図-9 圧力の鉛直分布

\section{5. ま め}

2 次元計算において実用化されてきている数值波動水 路 (CADMAS-SURF) を基に, 3 次元数值波動水槽 (CADMAS-SURF/3D) の開発を行った.また，効果 的な並列化システムの構築も行うことができた。

それを用いて，陸上遡上した津波の構造物に作用する 段波波圧の計算ならびに護岸に作用する津波段波波圧の 計算を行ったところ，実験と整合する結果が得られ，本 計算手法の妥当性が確認された。これにより段波波圧の ような砕波を伴う複雑な現象による波圧に対しても本計 算手法が有効であることがわかる.

今後は，接続境界等を検討し，広領域を効率よく，か つ実用に耐える精度で計算できる数值波動水槽を開発し ていく予定である.

\section{参 考 文 献}

五十里洋行 - 後藤仁志 - 酒井哲郎 (2004)：気液二相流型粒子法に よる砕波過程の数值シミュレーション, 海岸工学論文集, 第 51巻, pp. 111-116.

川崎浩司 ・ 中辻啓二 $(2002): 3$ 次元固気液多相流数值モデルの構 築とその検証, 海岸工学論文集, 第49巻, pp. 56-60.

数值波動水路の耐波設計への適用に関する研究会 (2002)：海域施 設の耐波設計に適用できる数值波動水路 (CADMAS-SURF) の研究・開発と将来展望, 土木学会論文集, No. 705/ II -59, pp. $1-17$.

永瀬恭一・島田昌也 (2000)：MARS 法を用いた数値波動水槽に関 する研究, 海岸工学論文集, 第47巻, pp. 46-50.

睦田秀実・河合ひろみ・安田孝志(1998)：C-CUP 法による気液界 面の直接数值計算, 海岸工学論文集, 第45巻, pp. 56-60.

睦田秀実 - 清水研一 - 土井康明 - 福田和宏 (2004)：CIP-EDEM 法 による自由液面と弾性体運動連成解析, 海岸工学論文集, 第 51巻, pp. 41-45. 